\title{
Relaciones de poder y apropiación del « otro » en relatos sobre iniciaciones shamánicas en el Chaco argentino
}

Florencia Tola

\author{
(2) OpenEdition \\ Journals \\ Edición electrónica \\ URL: http://journals.openedition.org/jsa/1849 \\ DOI: $10.4000 /$ jsa. 1849 \\ ISSN: 1957-7842 \\ Editor \\ Société des américanistes
}

Edición impresa

Fecha de publicación: 1 enero 2001

Paginación: 197-210

ISSN: 0037-9174

\section{Referencia electrónica}

Florencia Tola, «Relaciones de poder y apropiación del « otro » en relatos sobre iniciaciones shamánicas en el Chaco argentino », Journal de la société des américanistes [En línea], 87 | 2001 Publicado el 17 noviembre 2005, consultado el 21 abril 2019. URL : http://journals.openedition.org/ jsa/1849 ; DOI : 10.4000/jsa.1849 


\title{
RELACIONES DE PODER Y APROPIACIÓN DEL « OTRO » EN RELATOS SOBRE INICIACIONES SHAMÁNICAS EN EL CHACO ARGENTINO ${ }^{4}$
}

\author{
Florencia Carmen TOLA *
}

A partir de un relato sobre la iniciación shamánica toba se analiza la incorporación de elementos y personajes externos considerando especialmente las nociones de poder tales como son elaboradas actualmente en contextos peri-urbanos. En la iniciación shamánica se entrelazan los poderes de espíritus provenientes del imaginario de poblaciones vecinas con aquellos de los espíritus auxiliares reconocidos en la cosmología toba. Entre los nuevos seres con poderes iniciáticos analizaremos las figuras del gaucho y de ciertos personajes que aluden, la mayoría de las veces, a cargos (guardias y patrones) de alto rango en las relaciones interétnicas. Entender las nociones tobas de poder llevará a una comprensión de las relaciones entre diferentes tipos de personas en base a una jerarquía determinada por la posesión de poder shamánico y económico.

PALABRAS CLAVES : Chaco argentino, iniciaciones shamánicas, poder, relaciones interétnicas.

\section{Relations de pouvoir et appropriation d'autrui dans les récits d'initiations chamaniques du Chaco argentin}

Un récit sur l'initiation chamanique des Toba du Chaco argentin est le point de départ d'une analyse sur l'incorporation d'éléments et de personnages externes à leur culture. On insistera en particulier sur la façon dont les notions de pouvoir sont élaborées actuellement dans des contextes péri-urbains. Dans l'initiation chamanique, les pouvoirs des esprits provenant de l'imaginaire des populations voisines s'entrelacent avec ceux des esprits auxiliaires reconnus dans la cosmologie toba. Parmi les nouveaux êtres qui possèdent des pouvoirs initiatiques, on analysera, dans cet article, le gaucho et quelques personnages qui évoquent des positions d'un haut statut dans les relations inter-ethniques (guardias et patrones). L'étude des notions toba de pouvoir peut conduire à une compréhension des relations entre différents genres de personnes. Ces relations sont fondées sur une hiérarchie déterminée par la possession du pouvoir chamanique et économique.

MoTs CLés : Chaco argentin, initiations chamaniques, pouvoir, relations inter-ethniques.

* Antropóloga de la Universidad de Buenos Aires (Argentina). Becaria del Consejo Nacional de Investigaciones Científicas y Técnicas (CONICET) y Doctorante de l'EHESS - Universidad de Buenos Aires.

Journal de la Société des Américanistes, 2001, 87 : p. 197 à 210. Copyright @ Société des Américanistes. 


\section{Relations of power and the incorporation of the Other in shamanic initiation accoumts in the} Argentine Chaco

This article analyses the inclusion of external elements and personages in a narration concerning Toba shamanic initiation, focusing especially on notions of power such as they are elaborated nowadays in peri-urban contexts. In shamanic initiation the powers of spirits from the imaginary of neighboring villages are entwined with those of the auxiliary spirits present in the Toba cosmology. Among the new and foreign beings with initiatic powers, the figures of the gatcho and other personages who usually occupy high ranks in the interethnic relationship system (guardias and patrones) are considered. Understanding the Toba's notions of power allows one to shed light on the relations between different types of persons, on the basis of a hierarchy determined by the possession of shamanic and economic power.

KEY WORDS : Argentine Chaco, shamanic initiations, power, interethnic relations.

\section{INTRODUCCIÓN}

En este trabajo me interesa analizar algunas características del universo shamánico que lo convierten en un espacio concreto y simbólico de negociación y compenetración entre prácticas y creencias tobas y aquellas pertenecientes, en principio, al universo de representación de individuos no indígenas. La presencia del « otro » en los relatos sobre la iniciación da cuenta de cómo una tradición shamánica incorpora imágenes externas y se construye, al mismo tiempo, en torno a ellas constituyéndose como reflejo de distintos significados sociales que dan cuenta de las relaciones entre las poblaciones indígenas y la sociedad regional.

Las estrategias discursivas utilizadas en el relato de la iniciación se convierten en un medio de legitimación de la terapia shamánica ejercida en la población indígena y no indígena (criollos) del área. Consideramos, en efecto, que la apropiación de personajes y símbolos garantiza la continuidad de una práctica que se legitima ante el paciente a partir de su propia narración derivada de una alternancia constante entre identidad y alteridad. Los elementos incorporados de un muevo universo de sentidos e imágenes posibilitan que la terapia, más allá de sus valoraciones « exóticas » para el paciente criollo, cobre un grado de legitimidad por el hecho de poseer signos de un universo reconocido. Siendo tan fuerte en la región la devoción a numerosos Santos oficiales católicos y populares, el hecho de que los Santos, como imágenes legítimas, sean incorporados al universo shamánico de espíritus auxiliares, permite la resignificación del universo indígena, trascendiendo éste su condición de « salvaje » desde la mirada de los criollos. Por otra parte, continuando con la legitimación de la práctica shamánica, es interesante resaltar que una cantidad cada vez mayor de la población criolla, aun teniendo una actitud discriminatoria hacia los indígenas, acude a los shamanes tobas ante problemas personales y de salud. De esta manera, la imagen del indio se hace aún más ambigua itinerando en torno a, por una parte, concepciones despectivas y peyorativas (indio atrasado, ignorante y salvaje) y, por otra, la figura del shamán en tanto detentor de grandes poderes invisibles que aseguran el éxito de sus terapias. Esta incorporación del imaginario blanco referido a los lazos del indígena 
con fuerzas misteriosas se torna una herramienta que el shamán utiliza para garantizar la presencia del criollo como paciente efectivo y potencial de sus curaciones ${ }^{2}$. La práctica ritual de un shamán y los discursos que la legitiman nos permiten establecer; entonces, una relación entre diversas dimensiones como son las estrategias particulares del shamán y los aspectos históricos de las relaciones interculturales, plasmados éstos en la presencia de símbolos, imágenes y roles asociados con el blanco en los relatos shamánicos.

Para comprender las prácticas shamánicas - así como cualquier otra práctica social - cabe especificar el contexto en el que éstas se produjeron y producen y en el que los significados son constantemente elaborados y transformados. Es importante mencionar entonces que los tobas, pertenecientes a la rama lingüística guaycurú y autodenominados qom, viven en la región del Gran Chaco que abarca la República Argentina, Bolivia y Paraguay. Tradicionalmente eran cazadores-recolectores que se organizaban en bandas nómades y endógamas. En la actualidad, en Argentina se hallan establecidos en comunidades sedentarias agrícolas en las provincias de Salta, Chaco y Formosa. Desde los años sesenta una gran cantidad de aborígenes comenzó a migrar a las ciudades, atraída por los supuestos beneficios de las mismas (cercanía de una escuela, centro de salud y fuentes de trabajo). Se han creado, por lo tanto, recientes asentamientos indígenas en las cercanías de algunas de las grandes ciudades del país (barrios peri-urbanos de Resistencia, Formosa, Rosario, La Plata y Buenos Aires). El barrio peri-urbano en el que realicé el trabajo de campo por períodos de 4 meses entre 1997 y 1999 se denomina Namqom o Lote 68. Éste es un asentamiento que se sitúa a once kilómetros del centro de la ciudad de Formosa ${ }^{3}$ y que cuenta aproximadamente con 5000 individuos preferentemente tobas, aunque también viven en él varias familias wichis y pilagás. Recientemente, se han formado también algunas pocas familias entre individuos tobas y criollos que habitan en el barrio.

En Namqom, las relaciones que los tobas entablan con la sociedad regional son más intensas y estables que las que se establecen en las comunidades indígenas rurales, precisamente por la proximidad del barrio con la capital de la provincia. Son frecuentes también las relaciones entre Namqom y los barrios tobas de la ciudad de Buenos Aires, Resistencia y La Plata. Muchas de las familias establecidas en el Lote 68 tienen parientes que han migrado a la capital del país o a otras ciudades distantes de la región chaqueña. Se observa así una fuerte circulación de personas a través de varias provincias a las que se dirigen principalmente en busca de trabajos temporarios. En Namqom, la mayoría de los hombres realiza trabajos temporarios en la ciudad (changas), algunos pocos son empleados de la administración pública, y los ancianos $y$ algunos incapacitados para trabajar reciben mensualmente pensiones nacionales o provinciales. Las mujeres se encargan de la confección de artesanías en sus hogares y de su venta posterior en el centro de la ciudad. Es muy frecuente encontrar mujeres tobas en la ciudad mendigando alimento y ropa, casa por casa, junto con sus hijos. Suelen referir que si la actividad de antes era « mariscar », es decir, recolectar frutos en el monte, la de hoy en día consiste en "mercar», es decir, buscar mercadería en la ciudad y «mendigar » alimentos. No es poca tampoco la cantidad de personas que pasan sus días en el basural de la capital situado a las afueras buscando en él restos de alimentos y objetos útiles para sus hogares u objetos que puedan ser vendidos a recicladores de la ciudad. 
La presencia de instituciones y agencias provinciales y nacionales como una escuela primaria y secundaria, una comisaría, un centro de salud, un centro para jubilados y varios comedores públicos, permite el establecimiento de lazos más estables entre la población del barrio y los agentes y programas de dichas instituciones. A partir de dichas instituciones se entablan nuevos vínculos y relaciones como también diferentes modos de inserción en la sociedad regional. Al mismo tiempo, a través de múltiples formas de disciplinamiento se acelera el proceso de transformación de los indígenas en personas civiles que participan de un mismo proyecto de Nación que pretende incorporar lo diferente homogeneizándolo.

Luego de varios meses de trabajo de campo en Namqom, las narraciones sobre curaciones, espíritus auxiliares (natak) y viajes en busca de poderes shamánicos comenzaron a hacerse más frecuentes, en parte a raíz de mi interés por dichas temáticas, y en parte por el gusto que tienen algunos tobas de relatar experiencias shamánicas que les confieren, a quienes las vivenciaron, un alto grado de prestigio, poder y beneficios económicos. Entre los qom, los shamanes (pi'oGonaq) se encuentran asociados a diversas clases de espíritus, dentro de los cuales sus espíritus auxiliares les otorgan parte de sus poderes (piguishik) para efectuar curaciones o matar. La diversidad de las formas de transmisión de poder en la iniciación da cuenta de una característica del shamanismo que es justamente su capacidad de inclusión y resignificación. Podemos reconocer entre los tobas de Namqom dos formas, no necesariamente excluyentes, de recibir poder :

1. El iniciado hereda de algún familiar un objeto gelatinoso ${ }^{4}$ (el poder) desde pequeño $o$ antes de que ocurra la muerte de quien se lo otorgará ;

2. El individuo es elegido por un espíritu, aparecido en viajes oníricos o en el ámbito de la naturaleza, quien desde ese momento lo acompañará y le dará parte de sus poderes.

En este trabajo analizaré cómo el segundo tipo de iniciación se torna un espacio de apertura y transgresión en el que la alteridad es incorporada ${ }^{5}$. A partir de lo señalado, podemos referir que la manera en que el poder shamánico se produce y reproduce se lleva a cabo mediante procesos paralelos de personificación, multiplicación e incorporación. En cuanto a la personificación, los espíritus auxiliares pueden pertenecer a diferentes categorías, asociadas éstas a diversos estratos del cosmos. Los más comunes de dichos aliados son, por un lado, seres que por su intencionalidad, el uso de una lengua, su vida social y sus sentimientos son considerados personas que habitan en el universo, y, por otro lado, los dueños de aspecto humano o animal de las especies animales y ámbitos de la naturaleza. En cuanto a los procesos de multiplicación, puede mencionarse que algunos antepasados del shamán tienen la capacidad de convertirse en aliados, ampliando de este modo las categorías y tipos de espíritus auxiliares reconocidos ${ }^{6}$.

Hoy en día existen nuevos seres espirituales que son el resultado de la interacción de los tobas con individuos criollos y diversas agencias regionales. Estos espíritus exóticos son incorporados y ubicados en la cosmología toba junto con los seres tradicionalmente reconocidos, constituyendo una categoría de espíritus que, al igtal que los antiguos, posee una alta cuota de ambivalencia basada en la posesión de poder. Dicho poder es en sí mismo ambivalente ya que, como referimos, permite al shamán 
curar enfermedades y matar. Si el shamán ha logrado « amansar ${ }^{7}$ " (kanmanakchet) a sus espíritus, puede efectuar asesinatos ocultos ${ }^{8}$ movido por el deseo de venganza, envidia, por haber sido contratado por un tercero, como también puede utilizarlos para « levantar vidas », es decir, efectuar curaciones.

\section{INICIACIÓN SHAMÁNICA : PATRONES Y GAUCHOS}

Entre los seres con poderes iniciáticos incorporados de las poblaciones vecinas es interesante mencionar la figura de los gauchos y ciertos roles asociados en principio a la sociedad blanca, como son los reyes, patrones y guardias. Para referirme a estas figuras de poder voy a mencionar someramente algunos elementos de la inserción histórica del indígena chaqueño en el mercado laboral que posibilitó el contacto con gauchos, patrones, jefes y guardias.

Las bandas, principales unidades económicas del modo de producción cazadorrecolector, mantuvieron esta modalidad económica hasta fines del siglo XIX cuando se produjo su desarticulación a raíz de la expansión de la sociedad nacional (Gordillo 1992). Si bien hacia 1550 se inició el proceso de conquista del Chaco argentino, durante los siglos XVII y XVII la penetración española se vio limitada al envío esporádico de expediciones militares y al establecimiento de fortines en las zonas límites de la región (Métraux 1946, Gordillo 1992). Fue recién a mediados del siglo XIX e inicios del xx que la presencia del blanco se intensificó mediante campañas militares que lograron « pacificar » a los indígenas chaqueños. A partir de esos momentos se produjo la expansión del capital en la región, presencia manifestada en « el reclutamiento de la fuerza de trabajo indígena para los ingenios azucareros establecidos desde mediados y fines del siglo XIX en las últimas estribaciones subandinas de Salta y Jujuy [provincias del Noroeste argentino] » (Gordillo 1992, p. 8). En los ingenios, a raíz de la explotación sistemática a la que eran sometidos, de los prolongados períodos de tiempo que allí permanecían y de la cantidad de horas de trabajo diarias, los indígenas terminaron por ser « pacificados » y los levantamientos armados se hicieron cada vez más esporádicos. Como refiere Miller « los obrajes proporcionaron el primer contacto pacífico sostenido con el hombre blanco. Allí aprendieron el papel de peón asalariado. Aprendieron a obedecer a los patrones y a llevar a cabo tareas específicas de ellos requeridas » $(1979$, p. 61). Tanto los patrones agricultores como otros empresarios que llegaron a la región a lo largo del siglo XIX y xx (madereros, ganaderos, compradores de productos locales y vendedores de objetos de consumo) penetraron en el Chaco interesados en los posibles beneficios económicos y vieron al indígena « como un trabajador potencial para ser explotado, y su relación patronal [la del empresario] subordinó al indio » (ibid., p. 51).

Estas nuevas relaciones económicas y políticas crearon entonces nuevas relaciones sociales en las que los indígenas quedaron en posición de inferioridad respecto de los otros actores sociales. Por lo tanto, las imágenes de los roles de patrones, jefes y guardias que son insertadas en el universo shamánico hoy en día condensan, por un lado, las relaciones históricas que constituyeron y constituyen la identidad de criollos e indígenas tobas y, por otro, expresan la condición de superioridad y poder económico que dichos roles representan. 
La figura de los gauchos es especialmente asimilada a partir de los contactos que se entablaron en los lugares de trabajo con criollos del Paraguay y de la provincia de Corrientes. Es necesario especificar también que el gaucho posee una significación ambigua que alude a la conquista de grandes extensiones territoriales, entre ellas, el Chaco. En el proceso de ocupación de territorios nacionales, expansión de la línea de frontera y conversión de grandes extensiones de tierra en espacios productivos agropecuarios, el gaucho se constituyó como figura central y protagonista de dichos procesos. Como menciona Iñigo Carrera (1979), en Argentina la articulación con el mercado mundial tuvo como factor importante la expansión territorial hacia tierras indígenas a fin de que fuesen « incorporadas a la Nación » (citado por Wright 1997, p. 163). Sin embargo, hacia 1872, cuando José Hernández publica por primera vez su libro Martín Fierro, encontró una fuerte resistencia por parte de la elite intelectual del país. El libro, que narra los valores, penurias y vivencias de los gauchos en las fronteras con los indígenas, representa una apología, en términos de Wright, de « a social type that the European-oriented élite undervalued the most » $(1997$, p. 163).

Actualmente, la figura de los gauchos ha sido asociada por los tobas a la población rural criolla ya que tanto el gaucho como la población rural centra su actividad económica en el cuidado de estancias y ganado. Por otra parte, el acceso de los indígenas a los campos para cazar animales se ha visto cada vez más limitado a raíz de la presencia cada vez mayor de criollos en los campos cercanos a las comunidades. Dichos cuidadores de campos son quienes también persiguen a los cazadores que entran en sus terrenos para cazar animales que abundan más allí que en el monte (hawyaq). Por este motivo, los habitantes criollos rurales adoptan una connotación negativa a tal punto que sus acciones y poderes han sido trasladados a una figura imaginaria del gaucho que se encargaría, de modo semejante a los dueños de animales, de entregar poder a los iniciados o causarles enfermedades y matarlos. En muchas ocasiones los poderes de dicho personaje son equiparados a los del diablo ${ }^{9}$ adquiriendo aún más connotaciones negativas dadas por el temor que se le tiene y por sus capacidades de hacer daño a los seres que reciben sus poderes.

Para referirme tanto al proceso de integración que se produce entre estos personajes y los espíritus tobas, como al significado de los roles incorporados voy a partir de una experiencia específica del trabajo de campo. A lo largo de las estadías en el campo fui entablando relación con un señor de 60 años de edad, Federico, en la que él asumió el rol de « maestro » dispuesto a enseñarme la lengua y el significado profundo y múltiple de sus términos. Federico, considerando a sí mismo como « un hombre de edad por el camino que recorrí y los conocimientos que tengo », encontró en mí a una «blanca » que, con sorpresa para él, manifestaba interés por conocer las « historias de los antiguos ». Desde su perspectiva, los jóvenes de Namqom no se interesan en conocer las enseñanzas que los mayores desean brindar, sino que adoptan los modos de vida de los blancos dejando el qom laktaq, es decir; sus palabras.

En una ocasión, Federico me propuso ir a la casa de su hijo para que éste, reconocido shamán entre los qom y los blancos, me relatara su experiencia como shamán. En esa oportunidad, su hijo, Miguel, decidió contarme acerca de su iniciación en el shamanismo. Su narración da cuenta de la flexibilidad del universo shamánico y de cómo éste se construye precisamente a partir de la incorporación de 
elementos externos. La narración también permite visualizar el tipo de estrategia de legitimación que desempeña ante los pacientes, como también el significado atribuido a la noción de poder, retomando justamente lo referido a los procesos de incorporación y a las características de los personajes y roles incorporados. Estos nuevos elementos nos hablan no sólo de las características de los espíritus auxiliares sino también de la capacidad del shamanismo de convertirse en un espacio de absorción y resignificación de elementos nuevos.

Veamos en detalle partes de su narración :

"Yo soy el conocido acá en Formosa. Toda la gente me conoce no sólo en Formosa, en Buenos Aires también y en Córdoba, en Corrientes tengo muchos pacientes, en Ibarreta, en Fontana y Pirané, en Clorinda y en Asunción, Paraguay. Totalmente soy reconocido en esto [la curación]. Al recibir la promesa [poder] he sufrido mucho [...]. A mí me llevaron personas, son personas iguales que nosotros, son reyes de este trabajo [curar]. Ellos me llevaron al monte, estuve tres días en el monte. Me vinieron a buscar y me hicieron ir a un laguna grandísima. $Y$ vino a buscarme un yacaré grandísimo, me vino a buscar esa persona. Me dijo " Jiménez Ávalos te hace llamar, el patrón Avalos te hace llamar, así se llama nuestro patrón ". Me fui con él. Él se dio vuelta para entrar nuevamente en el agua y entramos. [...] Cuando llegamos a donde está la tierra [abajo del agua] estaba el guardia : era un pescado, igual que una palometa era su cara. Abrió la puerta y me dijo " mirá, nieto, ahora te vas por esta tierra ". De todo había abajo de esta tierra. Abajo hay mucha gente igual que nosotros pero son poderosos. Muchas veces uno dice que adentro de la tierra no hay nada pero adentro de la tierra hay mucha gente que tiene poder. No son como nosotros porque tienen mucho poder [...]. Me fui y llegué hasta donde están los gauchos, había ocho, tenían caballos pero eran de oro. Llegamos y me dijeron "sentáte, ahí está tu silla ". Y mi silla era araGanaklate'e [la madre de las víboras]. Después vino otro patrón, Santo León. Jiménez Ávalos le dijo " andá y tirále cinco tiros a este muchacho". Y agarró la escopeta y me tiró y me sangraba todo, las tripas veía totalmente. Me dijeron " paráte y decíle a la patrona que te cure ". Y araGanaklate'e me lamió todo el cuerpo y me quedé normal. Y después había un pozo grandísimo y abajo estaba lleno de víboras. Y vino Colón, el otro patrón y me dijo " tiráte ". Yo no quería pero me tiré al pozo. Vinieron todas las víboras, mi cara llena de víboras. Después me sacaron del pozo [...] y me dijeron " andá a dónde está la patrona ". Ella me lamió y quedé normal. Y después de eso me dijo : " desde acá te vas a tu casa, a los tres años curá a las criaturas ". Todos esos tiroteos, esas mordeduras es el poder que a mí me dieron [...]. A los doce años recibí ese poder. Empecé a curar criaturas y a los tres años a grandes y a los tres años a gente blanca [...]. Si el paciente me paga yo aviso a los que me están ayudando y ellos están contentos, y yo cada vez estoy más firme. Si no me pagan, ellos [los ayudantes] me retan. [...] Cada fin de año ellos me entregan alguna cosa, plata, lo que sea. La plata aparece sola, no les pido, me dan. Esta noche te van a acompañar, conocer cómo es tu sentimiento. Van a llegar cuando dormís, te quieren conocer $\$$.

Tal como se desprende de este relato, existen constantes referencias a figuras de poder (personajes y roles) cuya labor es central en la iniciación shamánica. Es interesante señalar que los términos que utiliza para referirse a los seres que le concedieron poderes shamánicos luego de intensas y peligrosas pruebas aluden, la mayoría de las veces, a cargos existentes en la sociedad nacional que los indígenas conocieron en las épocas en que trabajaban en los ingenios y plantaciones, y que conocen actualmente en sus trabajos temporarios en la ciudad de la provincia. Dichos cargos utilizados para hacer mención de los personajes míticos reconocidos tradicionalmente y de los nuevos iniciadores shamánicos dan cuenta, al mismo tiempo, de las relaciones de subordinación que los qom mantienen con las poblaciones e institucio- 
nes regionales y nacionales. En este relato, el término patrón alude específicamente a los espíritus de ancianos muertos que se convirtieron, luego de la iniciación, en los compañeros actuales del shamán. Con respecto a las características de estos iniciadores - como también de las personas que habitan en otros niveles del universo - es importante resaltar que si en base a ciertas cualidades son semejantes a los seres humanos, considerados a partir de otras características inherentes, ellos son jerárquicamente diferentes de éstos. Si, por un lado, son personas que tienen una lengua, que viven en poblados, cazan y pescan para obtener su alimento, por otro lado, son personajes que poseen mayor jerarquía en la escala de los seres existentes ya que están dotados de mayor poder, entendido como la capacidad de transformación de un estado de cosas y como la capacidad de transitar voluntariamente por varios niveles del universo. Es por eso que los humanos, seres que se encuentran en un rango inferior en la escala de los seres existentes si se los mide desde la posesión de poder shamánico, se encuentran siempre en la postura de quienes piden, suplican, anhelan, a la vez de que temen y sufren, el poder que los otros pueden conceder. Estos « otros » (los natak) están, en este caso, asociados a ciertos individuos que poseen también un mayor grado de prestigio y poder, aunque éste sea otra clase de poder. Los reyes, guardias y patrones están asociados a la prosperidad, al estatus social, a la autoridad y a altos rangos en las relaciones jerárquicas ${ }^{10}$. Si bien la naturaleza del poder es diferente - aunque no excluyente - ya que uno es un poder inherente a las personas no-humanas y a los shamanes, y el otro está ligado a la posición social del individuo y su condición económica, los poseedores de dichos poderes mantienen con los tobas un mismo tipo de relación jerárquica en la que éstos se encuentran en inferioridad de condiciones por no poseer y ambicionar simultáneamente porciones de un poder económico, político y shamánico. Sin embargo, como se desprende del relato, dicho poder está asociado, por su carácter ambiguo, a la experiencia de la muerte, al dolor y sometimiento en el que sus detentores - en este caso, patrones, reyes y guardias - se convierten, en la actualidad, en algunos de los encargados de la iniciación en un oficio ligado a los blancos.

La narración del shamán continúa con la incorporación de la figura de los gauchos. Lo que se desprende del relato es la asociación de estos personajes con la riqueza (tenían caballos... de oro) y con el poder iniciático, poder que los ubica junto con la madre de las víboras - ser cuyos poderes son altamente reconocidos (me dijeron " sentáte, ahí está tu silla ». Y mi silla era araGanaklate'e). Al mismo tiempo, en el imaginario toba la imagen de los gauchos está asociada, como referimos anteriormente, a los peligros de muerte materializados, por un lado, en el monte y los tesoros de oro ${ }^{11} \mathrm{y}$, por otro, en Satanás. La asociación de los gauchos con fuerzas demoníacas me ha sido referida en varias oportunidad por personas evangélicas. Una mujer de 40 años de edad que descree de los poderes shamánicos y que asocia a los gauchos con la obra del demonio, señala : «de los gauchos salieron los pi'oGonaq. Los gauchos te aparecen en sueños, te dan el poder. Te van a mostrar la riqueza que hay debajo de la tierra, pero te van a pedir que renuncies a tu familia ». Estos personajes están asociados a fuentes de poder shamánico y económico (sueños y tesoros) y tienen la capacidad de iniciar a los shamanes, asociando ambos poderes, al aparecérseles en sueños para indicarles dónde pueden encontrar riquezas escondidas. Pero, como si se tratara de un vínculo con el diablo, quien acepte ese poder debe estar dispuesto a 
renunciar a su vida entregando su alma a cambio. Esto se evidencia en las frecuentes referencias a que quienes encuentran tesoros escondidos y gauchos del monte sufren después lo que se denomina la «locura del oro »: enloquecen a raíz del contacto directo con los tesoros, los espíritus de los muertos que vigilan dichos tesoros y, con las fuentes de poder. Es interesante resaltar que, una vez que alguien desentierra un tesoro nunca podrá liberarse de la presencia de los alwalekpi (personas de la tierra) y espíritus de muertos que se vieron molestados por la invasión humana y el robo de las riquezas.

A partir de las asociaciones referidas, se evidencian las fuertes connotaciones que tienen las riquezas que pueden cambiar la vida de un individuo particular : ella produce un tipo de locura generada por la ambición y que durará para siempre en quien halló el tesoro. Se observa de este modo cómo el dinero y el progreso material e individual es valorizado en una sociedad cazadora-recolectora en la que prevaleció una ética igualitaria y solidaria (Karsten 1926, 1932) que está en la actualidad en procesos acelerados de transformación. La diferenciación social que produce el progreso económico genera sentimientos contradictorios que, en muchas oportunidades, conducen al deseo de la eliminación física del beneficiado.

El siguiente comentario relativo a la figura de los gauchos pertenece a un joven iniciado en el Evangelio y nieto de un reconocido shamán : «en el monte virgen existen los gauchos [...] Lo que querés les pedís y ellos te lo dan [...] Te dan un espíritu de gaucho. Los gauchos pertenecen a Satanás, son casi igual que los médicos [shamanes] ». Gauchos, shamanes y Satanás se encuentran asociados por el vínculo que representa el poder ligado no sólo - como ya hemos visto - a la riqueza material sino también a las capacidades de curar y matar. Si para muchas personas iniciadas en la religión evangélica, Satanás es una figura considerada fuente de poder que inicia a los shamanes, él es también el origen de los gauchos del monte, personajes que brindan sus poderes satánicos a los shamanes para que éstos se inicien en el camino « shamánico-satánico » que va acompañado de la capacidad de decidir sobre la vida y la muerte. No es un fenómeno casual que en la actualidad exista en Namqom un considerable aumento de las prácticas brujeriles que, a partir de la consumición de elementos de la víctima prolongados en objetos que estuvieron en contacto directo con ella, intentan eliminar a quienes progresan económicamente diferenciándose, de este modo, del resto del grupo ${ }^{12}$.

A fin de comprender las actuales valoraciones de elementos shamánicos resulta importante mencionar la presencia del pentecostalismo en el Chaco y su incidencia en el shamanismo. A mediados del siglo xx comenzaron a proliferar en la región chaqueña diversas iglesias pentecostales que generaron una relación de mutua incidencia entre sus prácticas y valores y las representaciones y prácticas shamánicas. Nombraremos aquí algunos elementos que permitieron tal intercambio entre uno y otro universo : la importancia de los líderes indígenas como intermediarios, la reinterpretación e incorporación de discursos e imágenes de poder y los tránsitos entre « tradición » y Evangelio gracias a elementos de significación aproximada.

El liderazgo indígena tradicional cobró un rol decisivo cuando las misiones pentecostales establecidas en Chaco y Formosa y las relaciones con los indígenas comenzaron a desintegrarse. Miller expresa que progresivamente « las congregaciones en las comunidades tobas continuaron creciendo y prosperando bajo liderazgo abo- 
rigen. Estos líderes encendieron un movimiento religioso vital... » $(1979$, p. 89), considerado posteriormente como un neo-shamanismo. En efecto, desde 1940 han surgido numerosas iglesias indígenas (la más antigua de ellas es la Iglesia Evangélica Unida) en torno a carismáticos líderes, pastores indígenas. En los « cultos » (denominación dada a los servicios religiosos regulares) los pastores son quienes dirigen la oración colectiva destinada a curar enfermedades, a la vez que pueden entrar en contacto directo con Dios (entidad con máximo poder) a partir de posesiones y visiones, que en otro momento sólo los shamanes podían tener. Como observamos, estas manifestaciones religiosas incorporaron desde su inicio elementos del Cristianismo Pentecostal y, desde entonces, los resignifican a la luz de los elementos del shamanismo.

Con respecto a la reinterpretación e incorporación de discursos e imágenes de poder, tal como refiere Miller (1967), los indígenas tuvieron un rol muy activo en la apropiación de las enseñanzas de los misioneros y de los mensajes bíblicos dando lugar a un nuevo marco religioso y ritual denominado el Evangelio (Wright 1990, 1992). Como señala Wright, " Evangelio is a qom category that has manifold facets. First, it refers to all evangelical denominations that contacted them. Second, it means aboriginal churches such as the Iglesia Evangélica Unida (United Evangelical Church) or other non-indigenous churches to which they belong [...]. It implies for them a complex re-reading of the world» $(1997$, p. 26). Las siguientes referencias nos resultan interesantes para el análisis del relato del shamán y para los comentarios de diversos individuos ya que se observan en ellas una crítica a los valores y prácticas tradicionales: "Evangelio's appearance coincides with a critique of tradition, which involves indigenous ways of life as a whole, regarded as " poor ", " dirty", " ignorant " [...]" (ibid., p. 74). Además, ser parte del Evangelio implica un nuevo estatus en el que el creyente se encuentra protegido de los poderes shamánicos peligrosos ya que pasa a estar en el ámbito en el que la Palabra de Dios actúa a modo de escudo. " As a power umbrella of sorts », menciona Wright refiriéndose al Evangelio, "it defends people from the attacks of evil forces - non-hmman beings' new label » (ibid., p. 75).

Por último, acerca de los tránsitos entre tradición shamánica y Evangelio, podemos mencionar diferentes instancias en las que se llevan a cabo dichos tránsitos a partir de significaciones aproximadas entre ellos. El énfasis pentecostal en la curación y en la posesión por el Espíritu Santo cobraron sentido a la luz de la ideología tradicional pudiendo, como refiere Miller, « reemplazar convenientemente al shamanismo [...] Los estados disociacionales del éxtasis - que comprendían el hablar en lenguas, el danzar, el caer y el entrar en trance - [...] eran todos reinterpretaciones de pautas shamánicas tradicionales » (ibid., pp. 115-116). Y, a diferencia del shamanismo tradicional en el que no todos podían ser shamanes, en las Iglesias pentecostales todas las personas tienen acceso al poder otorgado por Dios bajo la forma de diferentes « dones » (para curar; danzar, cantar, orar, tener visiones, etc.). Con respecto a elementos característicos de los "cultos», cabe subrayar el papel importante que desempeñan los cantos y la danza (Miller 1979). Así como en el shamanismo el canto otorgado por el espíritu auxiliar es central ya que a través de él el shamán efectúa la curación, en el culto los « cancionistas » (muchos de ellos conforman grupos musicales) poseen sus propios cantos que son ejecutados durante todas las etapas del culto (introduciendo testimonios, cantos de bienvenida y despedida, invitación a la plegaria, 
etc.). Con respecto a la danza que se lleva a cabo en las Iglesias, denominado « rueda » (baile colectivo circular), suelen mencionar en Namqom que las danzas que los " antiguos » bailaban eran muy semejantes a las actuales. Con la presencia anglicana en el Chaco occidental y la consecuente prohibición de danzas, cantos y terapias shamánicas (Miller 1979, Gordillo 1992), las danzas dejaron de ejecutarse hasta que la presencia protestante en el Chaco oriental dio lugar a que fuesen reinterpretadas y nuevamente ejecutadas en los contextos del Evangelio. En todos estos casos es posible observar algunos elementos que han permitido a la tradición shamánica manifestarse en contextos de la práctica evangélica pentecostal. Este mismo proceso de asimilación se produce en la práctica shamánica cuando el « otro », no necesariamente perteneciente al universo evangélico, es incorporado a partir de los discursos que narran y legitiman la iniciación.

Para concluir con la iniciación de Miguel voy a referirme al tema de la remuneración de la terapia con el que concluye su narración, ya que ella pondrá en evidencia las fuertes relaciones entre práctica shamánica y relaciones económicas. En efecto, es implícitamente acordado que, como contraprestación a la terapia shamánica, se realice un pago " voluntario » con algún objeto o alimento. Se menciona que a partir de entonces son los espíritus del shamán quienes quedan satisfechos con el tipo de intercambio efectuado. Miguel señala que los espíritus que lo ayudan a curar están contentos si él recibe una remuneración - preferentemente dinero - que evitará el enojo de éstos, enojo que puede cobrar la forma de una grave enfermedad para él. Si el paciente no paga la curación es el mismo shamán quien se encuentra en deuda con sus « patrones », quienes siempre reclamarán el pago. De esta forma, el riesgo de una contradicción ética generada por la remuneración excesiva solicitada por el shamán queda superado: el shamán cobra para satisfacción del espíritu que permite la terapia, sustrayéndose, de este modo, él mismo como beneficiario de la transacción económica. Sin embargo, un fenómeno nada usual es el hecho de que un shamán reciba regalos por parte de sus espíritus y, más aún, que estos regalos consistan en sumas considerables de dinero. $Y$ esto es lo que Miguel menciona que le ocurre. La relación de intercambio simultáneo entre shamán y espíritu, materializada en la ayuda para curar y la remuneración, estructura aún más el discurso ético que sustenta el pago de la terapia. El espíritu entrega algo al shamán que no es compensado por parte de éste. Según Miguel y su familia, cada fin de año él recibe grandes sumas de dinero que los patrones le dejan en su hogar. Este último hecho da cuenta de la fuerte asociación actual entre poderes shamánicos, espíritus iniciadores y poder económico, evidenciado en un aumento de los bienes materiales del shamán obtenidos a partir de las remuneraciones de los pacientes y del recibimiento de dinero por parte de los espíritus. Quedando el paciente y los espíritus satisfechos, la práctica shamánica se vuelve una instancia de regulación de riquezas en la que el shamán es el beneficiado final en una cadena compleja de acciones y efectos. Sin embargo, es frecuente escuchar comentarios referidos a la deshonestidad de los shamanes actuales. Se dice, en general, que los shamanes poderosos ya no existen y que los que hay hoy en día están más interesados en sus beneficios económicos personales que en curar realmente a las personas. Es por este motivo que se critican las enormes sumas solicitadas por un shamán luego de una terapia y la cantidad de objetos valiosos que pide, como también emergen estrategias 
de resistencia (como la brujería) que puedan nivelar las desigualdades sociales y los abusos de los shamanes.

\section{CONSIDERACIONES FINALES}

A lo largo de este trabajo me he referido a las prácticas shamánicas y al proceso de apropiación de símbolos e imágenes de universos que en principio les son ajenos. Esta capacidad de inclusión da lugar a una nueva configuración en la que tanto los elementos antiguos como los recientemente incorporados cobran nuevos sentidos a la luz de las actuales situaciones históricas. Los símbolos presentes en el universo shamánico se transforman constantemente, dando cuenta de la experiencia histórica y social del grupo. Los espíritus auxiliares tradicionalmente reconocidos, la figura de los gauchos, los nuevos personajes y roles se cargan de una significación que condensa las experiencias interculturales de las que los tobas son activos sujetos y quienes se ubican en relación de subordinación con respecto a la población regional y nacional. Refiriéndose a las relaciones generales de subordinación, Miller señala la importancia de los estándares criollos en la determinación del estatus entre los qom: «... tanto en la aceptación como en el rechazo de los estándares criollos, el estatus se determina por comparación con la sociedad blanca. Las categorías tobas se han vuelto insuficientes para determinar por sí mismas posiciones de estatus » (1979, p. 95).

En conjunto con las transformaciones de las condiciones de materialidad, el universo simbólico se transforma de manera concomitante y, en tal proceso, se nutre constantemente de elementos nuevos reapropiados y resignificados. Los gauchos, patrones y nuevos roles surgen en los contextos actuales y expresan, a partir de sus configuraciones dinámicas y flexibles, las nuevas experiencias shamánicas que lejos están de no expresar los conflictos sociales, económicos y políticos.

También he analizado el espacio de negociación generado entre el universo toba y los pacientes criollos a partir de la legitimación del discurso shamánico a partir de la incorporación de espíritus, personajes y roles del universo hegemónico de representación. El énfasis puesto en la economía política del shamanismo (apropiaciones de símbolos y sentidos, negociación de la identidad y uso estratégico de un discurso legitimador) dan cuenta de procesos históricos en los que los indígenas se insertan en la sociedad regional y nacional mediante estrategias de apropiación y resistencia, en las que los shamanes son activos sujetos de la transformación y cambio.

El poder, ligado también a las capacidades de vencer las fuerzas espirituales y a las habilidades para desplazarse por un universo poblado de nuevos personajes incorporando algunos de ellos, otorga al shamán un estatus que le permite elevar su nivel económico. Tal posicionamiento económico, a su vez, valida la práctica shamánica en la medida en que el shamán posee espíritus poderosos económicamente o que el poder de sus espíritus se manifiesta también a través del dinero. Cabe resaltar entonces que el poder shamánico queda vinculado tanto a una condición ontológica como a una posición económica en la que ambas se recrean reproduciéndose.

* Manuscrit reçu en février 2001, accepté pour publication en juin 2001. 


\section{NOTAS}

1. Quisiera agradecer a Federico y su hijo, Miguel, por el tiempo y las enseñanzas brindadas que dieron lugar a la realización de este trabajo. Expreso también mi gratitud al Dr. Pablo Wright por sus ricos comentarios y revisiones, a Carlos Salamanca por sus múltiples sugerencias que influyeron considerablemente en la forma final de este artículo, al Dr. Philippe Descola quien leyó y comentó atenta y generosamente la última versión de este trabajo y al Dr. Gastón Gordillo por sus estimulantes aportes y sugerencias.

2. Sobre el imaginario del salvaje en contextos shamánicos ver Taussig 1987.

3. Existe un servicio urbano de autobús que diariamente y a cada hora hace la ruta centro de la ciudad - barrio Namqom.

4. Varios iniciados shamánicos me han relatado acerca de los objetos escupidos por el shamán que está a punto de entregar sus poderes a otro. Dichos objetos, generalmente de consistencia gelatinosa, son escupidos directamente en la boca de quien será shamán, debiéndolo éste tragarlo inmediatamente. Pueden también ser otorgados en sueños al iniciado e introducidos en su cuerpo.

5. Cabe señalar que existen, en los contextos más abiertos al cambio (como es un barrio peri-urbano), otras modalidades menos compartidas de recibir poder : quien desea ser pi'oGonaq, por ejemplo, le pide a un pi'oGonaq que le venda parte de sus poderes, es decir, alguno de sus espíritus auxiliares. Esta compra, que puede superar la suma de cincuenta dólares, le permite a alguien que nunca tuvo en su familia un shamán de quien heredar poderes, comenzar a beneficiarse de las cualidades del espíritu. Señalan que existe un espíritu llamado roba bancos y que si uno lo posee puede ingresar a los bancos sin ser visto y llevarse así todo el dinero. Existe otro espíritu que le permite a su poseedor enriquecerse ya que logra transformar los billetes de sumas inferiores de dinero en billetes de sumas más alta.

6. Para mayor información sobre los diferentes tipos de espíritus y de estratos cosmológicos ver Miller 1979, Wright 1997.

7. Término utilizado por un iniciado shamánico para referirse al proceso de familiarización con el espíritu.

8. Ocultos en la medida en que los shamanes envían en sueños sus poderes dañinos (proyectiles, misiles, la bala india, bichos) a personas a las que desean dañar, es decir, a las víctimas de sus acciones guiadas por los espíritus auxiliares. Son ocultos tanto para quienes no tienen poder como para los blancos (sobre la invisibilidad de los poderes shamánicos ver Gordillo 2000).

9. En el oeste formoseño, según refiere Gordillo (2001, comunicación personal), los tobas asocian constantemente al gaucho con los payak o diablos. Según su perspectiva, la imagen del gaucho proviene de los criollos mismos : un gaucho que anda por el monte y es, al mismo tiempo, el diablo.

10. Con respecto a la relación entre indígenas tobas y los criollos, Wright senala : " there is a perception that Whites have access to abundant goods and that they are almost always patrones (" bosses "), enjoying a superior position vis-a-vis the qom 》 (1997, p. 266).

11. Entre los tobas y la población regional - argentina y paraguaya - es frecuente la referencia a tesoros escondidos en la región chaqueña. Suele mencionarse que durante la guerra de la Triple Alianza (1856) en la que la República Argentina, Brasil, Uruguay lucharon contra Paraguay, los habitantes adinerados de la región escondian sus riquezas bajo tierra en medio del monte o en campos cercanos a los poblados. Luego de la guerra, muchos de tales tesoros no fueron recogidos o no fueron hallados quedando, por lo tanto, escondidos en los sitios en que habían sido enterradas.

12. Sobre el aumento de las prácticas y acusaciones de brujería en contextos peri-urbanos tobas ver Salamanca y Tola 2001.

\section{BIBLIOGRAFÍA}

GoRDILlo, Gastón, 1992. — « Cazadores-recolectores y cosecheros. Subordinación al capital y reproducción social entre los tobas del oeste de Formosa ", en Capitalismo y grupos indigenas en el Chaco Centro-Occidental (Salta y Formosa)/1, Trinchero H., D. Piccinini y G. Gordillo, Centro Editor de América Latina, Buenos Aires. 
-, 2000. - «A political economy of shamanic forms of contention in the Argentine Chaco », ponencia presentada en American Anthropological Association, San Francisco.

IÑgo Carrera, Nicolás, 1979. - La violencia como potencia económica : Chaco 1879-1940, Centro Editor de América Latina ( $\left.\mathrm{n}^{\circ} 11\right)$, Buenos Aires.

JACKSON, Michael, 1990. — « The man who could turn into an elephant : shape-shifting among the Kuranko of Sierra Leone ", en M. Jackson and I. Karp (eds.), Personhood and Agency. The Experience of Self and Other in African Culture, Smithsonian Institution Press, Uppsala.

KARSTEN, Rafael, 1926. - The civilization of the South American Indians, Kegan Paul, Trench, Trubner and $\mathrm{Co}$, Londres.

—, 1932. - "Indians tribes of the Argentine and Bolivian Chaco. Ethnological Studies », Societas Scientiarum Fennica, 4 (1), pp. 10-236.

MÉtraux, Alfred, 1982 [1946]. - Les Indiens de l'Amérique du sud, Gallimard, Paris.

—, 1967. - Religions et magies indiennes d'Amérique du sud, Gallimard, Paris.

MiLLER, Elmer, 1967. - Pentecostalism among the Argentine Toba, Ph. D. diss., University of Pittsburgh.

—, 1979. - Los Tobas argentinos. Armonía y disonancia en una sociedad, Siglo XXI, México.

Salamanca, Carlos y Florencia Tola, 2001. - «Paradojas de la modernidad : prácticas brujeriles en un grupo indígena del Chaco argentino ", ponencia presentada en el $I^{\gamma}$ Encuentro del Corredor de las Ideas del Cono Sur, Asunción, Paraguay.

TAussig, Michael, 1987. - Shamanism, Colonialism, and the Wild Man : a study in terror and healing, University of Chicago Press, Chicago / London.

TolA, Florencia, 2001. — « La simbologia de la luna en el imaginario masculino y femenino de los tobas orientales (qom) del Chaco Argentino ", Avá, Revista de Antropologia (Posadas, Argentina), 3, pp. 75-88.

Wright, Pablo, 1984. - «Quelques formes du chamanisme toba », Société suisse des Américanistes, 48, pp. 29-35.

-, 1990. - « Crisis, enfermedad y poder en la Iglesia Cuadrangular Toba », Cristianismo 3 Sociedad, 28 (3), pp. 15-37.

—, 1992. — «Toba pentecostalism revisited », Social Compass, 39 (3), pp. 355-375.

-, 1997. - Being-in-the-dream. Postcolonial Explorations in Toba Ontology, Ph.D. diss., Temple University. 